\title{
Detection performance assessment of hand-held mine detection systems in a procurement process: test set-up for MDs and MD/GPRs
}

\author{
Arnold J. Schoolderman ${ }^{\mathrm{a}^{*}}$, Jacques H.J. Roosenboom ${ }^{\mathrm{b}}$ \\ ${ }^{a}$ TNO Defence, Security and Safety, P.O. Box 96864, 2509 JG The Hague, The Netherlands \\ ${ }^{b}$ Ministry of Defence, Defence Materiel Organisation, P.O. Box 90822, 2509 LV The Hague, The \\ Netherlands
}

\begin{abstract}
The Engineers Centre of Expertise of the Royal Netherlands Army (RNLA) has conducted a study on countermine in peace operations. This study, finished in 2002, concluded that the final solution to countermine will depend in the first place on better detection of buried low-metal mines, e.g. by direct detection of the explosive components in mines. Until such detection systems are available, intermediate solutions are necessary in order to assure freedom of movement in peace operations. Because countermine operations consist of a number of different activities (area preparation, detection, clearance, etc) and the suitability of the different types of available equipment depends on the scenario, the toolbox concept for countermine equipment was adopted. In 2003 a procurement process was started in order to fill this toolbox with commercial-off-the-shelf and military-off-the-shelf equipment.

The paper gives a concise description of the study on countermine operations and the procurement process, and subsequently focuses on the set-up of the tests that were conducted in the framework of the procurement of hand-held mine detection systems, like metal detectors and dual-sensor mine detectors. Programs of requirements for these systems were drawn up, aiming at systems for general use and special purpose systems. Blind tests to check the compliancy to the detection performance requirements were designed and conducted in the short timeframe that was available in the procurement process. These tests are discussed in this paper, including the set-up of the test lanes, the targets used and their depths, and the role of the operator. The tests of the capability of the detectors to discriminate small targets adjacent to large targets were conducted according the guidelines of the CEN Workshop Agreement on metal detector tests. Although the results of the tests are commercially confidential, conclusions and lessons learned from the execution of these tests are presented.
\end{abstract}

Keywords: Mine, detection, metal detector, test, performance

\section{ROYAL NETHERLANDS ARMY COUNTERMINE STUDY}

In 2001 - 2002 the Engineers Center of Expertise of the Royal Netherlands Army (RNLA) conducted a comprehensive study on countermine operations and the necessary equipment [1]. The aim of this study was to formulate recommendations with respect to research, development and procurement for countermine equipment in order to anticipate better to expeditionary peace operations in the near future. In the study the different aspects of countermine are described and the role of countermine operations in peace enforcement and peace keeping is discussed.

The study concludes that currently the RNLA has only manual prodders and hand-held metal detectors for the detection of mines, which are partially out of date. Other available countermine equipment include heavy and bulky mine field marking equipment and non-dedicated plastic explosives and neutralization means. Since 1998 the RNLA has a limited number of mine reconnaissance sets for peace keeping operations available, but these are not complete yet.

The study foresees a technological solution of the mine detection problem in detection of explosives in the ground in one step, but this solution will not be available before 2012. Apart from a study on the feasibility of dogs for mine detection in the RNLA, a temporary solution for the mine detection problem is necessary, e.g. by combining different sensor technologies in order to obtain a high detection probability and a low false alarm rate. The study recommends purchasing commercial-off-the-shelf counter mine equipment in order to tide over the coming ten years, and put up with their disadvantages and limitations. In order to cope with all different activities that are part of a countermine operation,

*arnold.schoolderman@tno.nl; phone +31 70374 0793; fax +31 70374 0654; www.tno.nl 
such as detection, neutralization, mine intelligence, etc, the countermine toolbox concept was adopted. This toolbox will be filled with commercial-off-the-shelf equipment, such as hand-held detections systems.

\section{REQUIREMENTS FOR HAND-HELD DETECTION SYSTEM}

To obtain commercial-off-the-shelf equipment for the countermine toolbox a procurement was set up according to the procurement procedure that is used by the MoD, i.e. subsequently an inventory of the market, requests for information to the potential suppliers, evaluation of the information received, definition of the requirements for the toolbox components in a Program of Requirements and a request for quotations send to the selected potential suppliers. Based on the quotations and the compliancy of the equipment offered, negotiations for the procurement will be started. Although Program of Requirements were defined for all components of the countermine toolbox separately, in this paper we will only consider the Programs of Requirements for the 'General Purpose Hand-Held (Mine) Detector (GPHHMD)' [2] and the 'Special Purpose Hand-Held (Mine) Detector (SPHHMD)' [3]. Apart from a description of the use as intended by the RNLA of these detectors in countermine operations, these Programs of Requirements contain sections on functional requirements, requirements on construction, preservation, packaging, etc. and requirements on logistical aspects, such as maintenance and training of personnel. The functional requirements deal with detection performance of the detectors and influences that can degrade this performance, e.g. weather and climatic conditions during operational use and electromagnetic compatibility, and ergonomics and transport issues (dimensions and weight). The main requirements related with the detection performance for the GPHHMD are given below.

- The system (i.e. the detector) shall detect metal containing mines of f.e. the types PMN, PMN-2 and type PMA-2 with RO-1 fuse and UXO, f.e. hand grenade M84, that are buried at a minimum depth of $200 \mathrm{~mm}$ (top of mine - soil surface) in non-magnetic soil while the detector is between 0 and $50 \mathrm{~mm}$ above the ground.

- The system shall detect low-metal mines of f.e. the types PMA-2, PMA-3 and type 72a and UXO, f.e. hand grenade M84, that are buried at a minimum depth of $50 \mathrm{~mm}$ (top of mine - soil surface) in non-magnetic soil while the detector is between 0 and $50 \mathrm{~mm}$ above the ground.

- With the system localization of detected buried metal-containing landmines shall be possible with an accuracy of $50 \mathrm{~mm}$ relative to the centre of the metal mass.

- With the system the operator shall be able to differentiate between minimum (low) metal mines and metal cased mines laid at a minimum of $200 \mathrm{~mm}$ apart.

The main detection performance requirements for the Special Purpose Hand-Held (Mine) Detector differ only one point: in stead of mines buried in non-magnetic soil, the SPHHMD shall detect these mines also buried in magnetic soil.

\section{DETECTION PERFORMANCE TEST}

Five companies responded to the Request for Quotation for the hand-held mine detectors. Four of the offered detectors are conventional metal detectors designed especially for mine detection and one system is a dual-sensor detector in which a metal detector and a ground penetrating radar are combined. All five claimed that their product meets the requirements for both the General Purpose Mine Detector (GPHHMD) and the Special Purpose Mine Detector (SPHHMD). However, actual prove of compliancy of the products with the requirements was lacking, or a reference was given to test reports that were not publicly available.

In order to obtain an unbiased image of the detectors' performance, tests were set up. In these tests the detection performance and the ergonomics of the detectors were considered. The tests on the detectors' ergonomics were set up and conducted by the Royal Engineers, the intended end-users of the detectors. The detection performance test was set up and conducted by TNO Defence, Safety and Security, The Hague (the former TNO Physics and Electronics Laboratory). Because of the planning of the requirement process, it was aimed at a detection performance test that could be conducted at a short term, including the preparations of the test site. This was one of the reasons to use the test lanes at the mine detection test facility of TNO in The Hague.

In the set up of the detection performance test, special attention was given to the combined metal detector - ground penetrating radar that was offered by one manufacturer. Since this system is much more expensive than the offered conventional metal detectors and asks for more training of the operators, a plus value of this system over a conventional metal detector was expected to be shown in the tests. A plus value could be for instance the rejection of clutter. 


\subsection{Test procedure}

The detection performance tests were set up as blind tests: the locations of the buried targets were not known to the operators. Three different tests can be distinguished. For the conventional metal detectors two tests were set up: a test of the detection performance and location accuracy for a number of specific targets in different soils and a test of the ability to discriminate with the detector under test between low metal targets and targets with a high metal content that are buried close to each other. The second test is set-up according to the guidelines given in the CEN Workshop Agreement on metal detector test and evaluation, section 9.4 'Resolution of adjacent targets' [7]. The operators were asked to mark the location of detected targets with a porcelain marker (size: $2 \times 2 \mathrm{~cm}$ ).

For the dual-sensor detector, an extra test was designed. In this test, the ability to discriminate between mine-like targets and clutter with this detector is investigated. The operator was asked to mark the locations of detected mine-like targets and clutter with the help of markers with a different colour.

\subsection{Test lanes}

TNO's mine detection test lanes were designed and built in 1997 for a national humanitarian demining research project with the aim to demonstrate improved mine detection performance of a multi-sensor system, both hand-held and vehicle-mounted. In the first phase of that project the test lanes were used to select the most suitable commercial-offthe-shelf detectors to combine in the intended multi-sensor systems.

The mine detection test facility of TNO, The Hague, consists of 6 outdoor test lanes. Each lane is $10 \mathrm{~m}$ long, $3 \mathrm{~m}$ wide and $1.5 \mathrm{~m}$ deep. The lanes are constructed out of wood and plastics, and the areas between and around the lanes are free of metal. Each lane contains a different soil type: sand, clay, peat, ferruginous soil, forest soil and sandy soil with a variety of rocks and a top layer of grass. Because of import regulations, only soil types were used that can be found in the Netherlands.

Only three of the six outdoor lanes were used for the detection performance tests in the framework of the procurement process: the lanes with sand, ferruginous soil and forest soil. Details on the composition of the soils are given in [4]. The electromagnetic soil properties that are considered to be the most important for the performance of metal detectors have been measured for four lanes in the framework of the International Pilot Project for Technology Co-operation, which was conducted in 1999-2000 [5], [6]. The results of these measurements for the lanes with sand and ferruginous soil are given in table 1. These measurements were conducted with a Geonics EM38 for the conductivity and the Bartington MS2 magnetic susceptibility meter. Experience has learned that in the lane with forest soil a considerable amount of metal clutter is present.

Different areas in these lanes were marked with coloured tape: two areas where targets were buried for blind tests, an area for calibration purposes, a small area in us by other projects and, in the ferruginous soil lane and the forest soil lane, an area for conducting tests of the detector's ability to discriminate between adjacent targets. Figure 1 shows the ferruginous soil lane with these different areas.

In order to make the use of any visual indications of target burial impossible for the operators of the metal detectors under test, the outdoor lanes were covered with a thin black plastic sheet. Since it was thought that this sheet and especially moisture that accumulates under the sheet, could influence the performance of the GPR in the dual-sensor detector, this sheet was removed for the tests of this detector.

Table 1: EM-properties of the soil in two of the test lanes at TNO, The Hague.

\begin{tabular}{|l|l|l|l|l|l|l|l|l|l|}
\hline \multirow{2}{*}{ Lane } & \multicolumn{3}{l}{$\begin{array}{l}\text { Conductivity EM38 } \\
\text { horizontal }[\mathrm{mS} / \mathrm{m}]\end{array}$} & \multicolumn{2}{l|}{$\begin{array}{l}\text { Conductivity EM38 vertical } \\
{[\mathrm{mS} / \mathrm{m}]}\end{array}$} & \multicolumn{2}{l}{$\begin{array}{l}\text { Susceptibility MS2 } \\
\left(\mathrm{x} 10^{\wedge} 5\right)\end{array}$} \\
\cline { 2 - 11 } & range & mean & SD & range & mean & SD & range & mean & SD \\
\hline \#1 sand & $-10.4 ; 5.6$ & 3 & 4 & $6.9 ; 10.7$ & 8 & 1 & $1 ; 9$ & 3 & 2 \\
\hline \#4 ferruginous & $-2.1 ; 3.3$ & 2 & 1 & $3.6 ; 6.4$ & 4 & 1 & $13 ; 48$ & 27 & 9 \\
\hline
\end{tabular}

Apart from the three outdoor test lanes, a small indoor test lane was constructed. This test lane, with a length of $2.5 \mathrm{~m}$ and a width of $1.5 \mathrm{~m}$, consisted of a $15 \mathrm{~cm}$ layer of magnetite, imported from Norway, on a $3 \mathrm{~m}$ deep bed of sand. Figure 2 shows this test lane. A strip of $1.5 \times 0.5 \mathrm{~m}$ was used for calibration purposes; the targets were buried in the remaining area. Although no figures on the magnetic susceptibility of the magnetite layer are available, the measurement of the Ground Reference Height as described in [8] results in a value of approximately $45 \mathrm{~cm}$, showing that this is a very severe type of magnetic soil for metal detectors to cope with. 


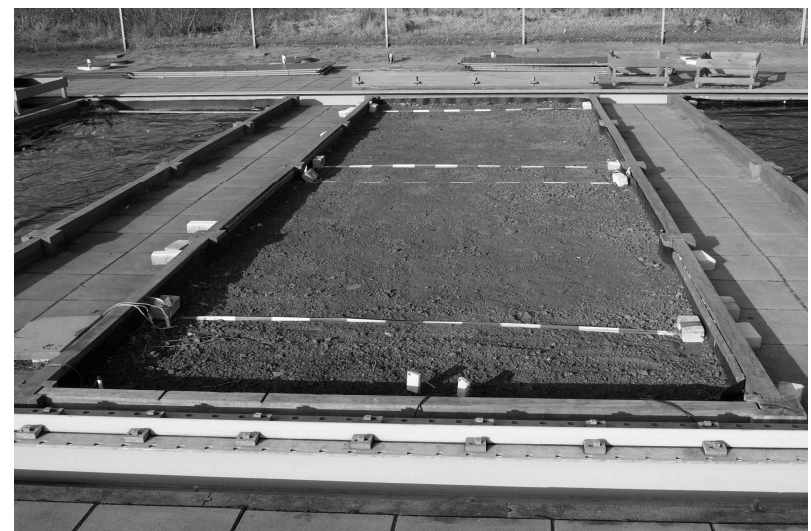

Figure 1: Test lane with ferruginous soil. The different test areas are marked with two-colour tape.

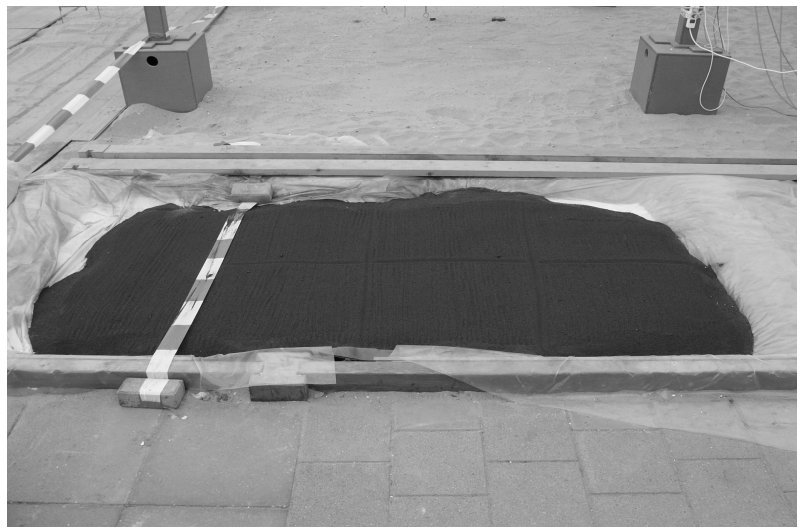

Figure 2: Test lane with magnetite. The area on the left hand from with two-colour tape is used for calibration; the targets for the test are buried in the area right from the tape.

\subsection{Targets}

Again, in order to save time in the procurement process, readily available targets were preferred for the tests. A number of suitable targets for the tests were already buried in the lane with ferruginous soil and the lane with the grass top layer at depths up to $10 \mathrm{~cm}$ for other detection equipment tests that were conducted in 2003 and earlier. However these targets were buried in a pattern that may be easy for the operators to recognize and hence may influence the results of the tests. For that reason, some of these targets were removed from the lanes so that the pattern was obscured.

The following inert mines and mine simulants were used in the ferruginous soil lane and the forest soil lane for the detection performance test: PMN, M14, wooden box AP-mine, NR22 with and without metal detection ring and NR24. Figure 3 shows these targets. These targets were buried at depths of $1 \mathrm{~cm}, 5 \mathrm{~cm}, 6 \mathrm{~cm}, 10 \mathrm{~cm}$ and $20 \mathrm{~cm}$ (the latter only for the inert PMN mines that contain relatively much metal), and flush buried. Table 2 gives an overview of the quantities of these targets and their depths. Since the sand lane was set up to test, apart from the detection performance, the ability of the dual-sensor system to discriminate between mine-like objects and clutter, also well defined objects that represent clutter were buried in that lane. These latter objects consisted of soft drink cans, small calibre rounds, detonators from the M14 and fuses from the wooden box AP-mine and butterfly mine, and were buried at depths of 5 and $10 \mathrm{~cm}$. In the magnetite lane, M14 targets were buried at $5 \mathrm{~cm}$ and PMN and NR22 with detection ring at $10 \mathrm{~cm}$. The distance between adjacent targets was in all cases equal or more than $50 \mathrm{~cm}$.

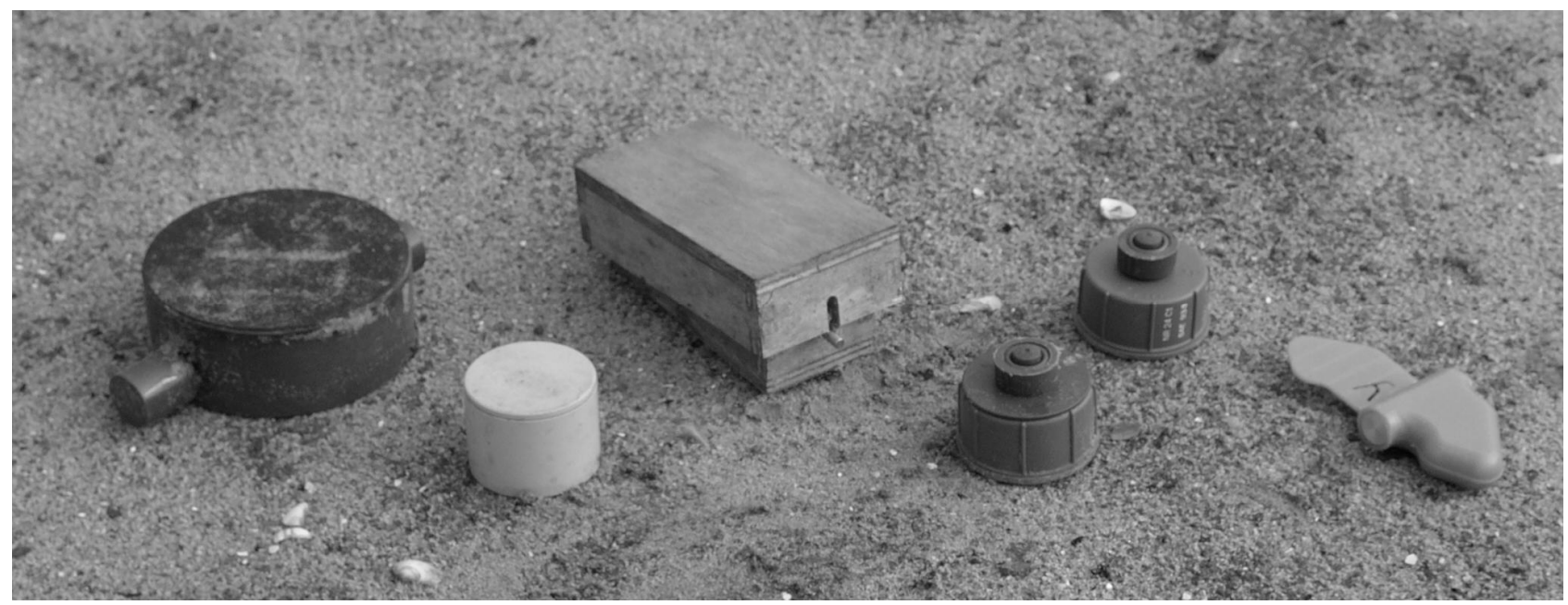

Figure 3: Targets used in the detection performance tests: PMN, M14, wooden box AP-mine, NR22 with detection ring, NR24 and Butterfly mine (from left to right) 
Table 2: Overview of targets in the test lanes and their burial depths.

\begin{tabular}{|c|c|c|c|}
\hline Lane & Target & $\begin{array}{l}\text { Quantity (per } \\
\text { depth) }\end{array}$ & $\begin{array}{l}\text { Burial depths } \\
(\mathrm{cm})\end{array}$ \\
\hline \multirow[t]{11}{*}{ Sand } & AP-wood & 3 & 5 \\
\hline & Fuse from AP-wood mine & 3 & 5 \\
\hline & M14 & 9 & 5 \\
\hline & M14 detonator & 7 & 5 \\
\hline & PMN & 4,4 & 10,20 \\
\hline & NR22 (no detection ring) & 5,1 & 5,10 \\
\hline & NR22 with detection ring & 3,3 & 5,10 \\
\hline & Butterfly mine & 3 & 5 \\
\hline & Fuse of Butterfly mine & 3 & 5 \\
\hline & Bullet round & 3,1 & 5,10 \\
\hline & Softdrink can & 1,1 & 5,10 \\
\hline \multirow[t]{4}{*}{ Ferruginous soil } & M14 & 6,9 & 1,6 \\
\hline & PMN & $6,6,7$ & $1,6,20$ \\
\hline & NR22 (no detection ring) & 6,6 & 1,6 \\
\hline & NR22 with detection ring & 2,4 & 5,10 \\
\hline \multirow[t]{5}{*}{ Forest soil } & AP-wood & 4,2 & 5,10 \\
\hline & M14 & 5,2 & 5,10 \\
\hline & PMN & 2,4 & 10,20 \\
\hline & NR24 & 4,4 & Flush, 10 \\
\hline & NR22 with detection ring & 4 & 10 \\
\hline \multirow[t]{3}{*}{ Magnetite } & M14 & 6 & 5 \\
\hline & PMN & 5 & 10 \\
\hline & NR22 with detection ring & 3 & 10 \\
\hline
\end{tabular}

For the test on the resolution of adjacent targets, iron discs with a diameter of $5 \mathrm{~cm}$ and thickness of $3 \mathrm{~mm}$ were used, together with iron balls with diameters of 3,5 and $7 \mathrm{~mm}$. These targets were buried at a depth of $10 \mathrm{~cm}$ in the assigned areas in the test lanes with ferruginous soil and forest soil. The distance from the centre of the discs and the iron balls was $20 \mathrm{~cm}$.

\subsection{Operators}

In the planning of the procurement process no time was available to train operators for the detectors under test. Since experience with the detector under test, apart from training, is considered as an important factor for successful use of the detector, the manufacturers of the detectors were asked to make their own operator available for the tests. All five manufacturers took up this opportunity. The operators were instructed on the aim and procedure of the test with the help of a written test plan and an oral instruction before the start of the actual test. The assigned calibration areas in the test lanes were used by the operators for the set-up of the detectors.

\subsection{On the results}

Since the test discussed here is part of a procurement procedure that is still running, the test results are regarded as commercially confidential. However, the results for the conventional metal detectors are shown here without making any reference to specific detector types in Table 3 to 5. Since the metal detectors were not tested on the lane with sand, only the results for these detectors for the ferruginous soil lane, forest soil lane and magnetite are given in this table. One metal detector, here denoted as detector 4, was not tested on the magnetite lane, because the operator was not able to set up this detector for this particular soil type without any additional tools (computer with appropriate signal processing software).

For the scoring of the detection results on the ferruginous soil and forest soil lanes, a halo radius of $15 \mathrm{~cm}$ is used, while a halo radius of $10 \mathrm{~cm}$ is used for the magnetite test lane. The halo radius is the radius of the circle around the actual location of a target, within which an alarm indication (placed marker) is considered a correct detection [7]. A halo radius of $15 \mathrm{~cm}$ results not in a significant change the scoring for the lane with magnetite. 
From the results shown in these three tables it is clear that the detection performance of the four modern, commercialof-the-shelf metal detectors differ considerably. The best performing detector, detector 1 , has on average twice as much correct detections as the detector 4 , the detector with the least number of correct detections. Although the absolute number of false detections is also much higher for detector 1, the ration of correct detections to the number of placed markers is also better for detector 1.

The M14 targets can be detected with the better performing detectors (detectors 1 and 2) up to a depth of $6 \mathrm{~cm}$. These targets are very hard to detect at a depth of $10 \mathrm{~cm}$. The same holds for the wooden AP-mine: at a depth of $5 \mathrm{~cm}$ it is detectable, but not at $10 \mathrm{~cm}$. The minimum metal NR22 target can not be detected with the tested metal detectors. Some PMN targets were detected up to a depth of $20 \mathrm{~cm}$ in the ferruginous soil lane with all four detectors, but in the forest soil lane only one of these targets was detected at this depth with detector 1 .

Discrimination between adjacent high and low metal targets is difficult with the metal detectors under test. With the best performing detector the metal disc and the adjacent iron ball could be discriminated in 3 cases (out of 8).

It was expected that the ferruginous soil would be more difficult for the metal detectors than the forest soil. This expectation is not apparent form the test results, although this may be due to the different target sets used in the ferruginous soil and forest soil lanes. As expected, the magnetite appeared to be a very severe soil type for metal detectors.

Due to commercial confidentiality no results of the test of the dual-sensor detector can be given here. However, it is concluded that with the used test procedure on the lane with sand, i.e. marking mine-like objects and clutter distinctively, a plus value of such a detector with respect to a conventional metal detector can be shown.

Table 3: Detection results of the four metal detectors for the lane with ferruginous soil.

\begin{tabular}{|c|c|c|c|c|c|c|}
\hline \multicolumn{2}{|c|}{ Ferruginous soil } & \multirow{2}{*}{$\begin{array}{r}\text { halo: } 15 \mathrm{~cm} \\
\text { quantity }\end{array}$} & \multirow[b]{2}{*}{ detector 1} & \multirow[b]{2}{*}{ detector 2} & \multirow[b]{2}{*}{ detector 3} & \multirow[b]{2}{*}{ detector 4} \\
\hline target & depth (cm) & & & & & \\
\hline NR22 & -1 & 6 & 0 & 0 & 0 & 0 \\
\hline NR22 & -6 & 6 & 0 & 0 & 0 & 0 \\
\hline $\mathrm{M} 14$ & -1 & 6 & 6 & 5 & 5 & 2 \\
\hline $\mathrm{M} 14$ & -6 & 9 & 7 & 8 & 1 & 1 \\
\hline PMN & -1 & 6 & 4 & 3 & 3 & 6 \\
\hline PMN & -6 & 6 & 5 & 4 & 3 & 2 \\
\hline PMN & -20 & 7 & 2 & 2 & 2 & 1 \\
\hline NR22+ring & -5 & 2 & 2 & 1 & 2 & 2 \\
\hline NR22+ring & -10 & 4 & 3 & 4 & 4 & 4 \\
\hline disc/ball & -10 & 3 & 1 & 0 & 0 & 0 \\
\hline \multicolumn{3}{|c|}{ \# correct detections: } & 30 & 27 & 20 & 18 \\
\hline & \multicolumn{2}{|c|}{ \# used markers: } & 50 & 49 & 45 & 28 \\
\hline
\end{tabular}

Table 4: Detection results of the four metal detectors for the lane with forest soil.

\begin{tabular}{|l|c|c|c|c|c|c|}
\hline Forest soil & halo: $15 \mathrm{~cm}$ & & detector 4 \\
\hline target & depth $(\mathrm{cm})$ & quantity & detector 1 & detector 2 & detector 3 & detect \\
\hline NR24 & 0 & 4 & 2 & 2 & 2 & 2 \\
\hline NR24 & -10 & 4 & 2 & 2 & 2 & 1 \\
\hline AP-wood & -5 & 4 & 2 & 3 & 2 & 0 \\
\hline AP-wood & -10 & 2 & 0 & 1 & 0 & 0 \\
\hline NR22+ring & -10 & 4 & 3 & 4 & 4 & 3 \\
\hline M14 & -5 & 5 & 4 & 1 & 0 & 1 \\
\hline M14 & -10 & 2 & 1 & 0 & 0 & 0 \\
\hline PMN & -10 & 2 & 2 & 1 & 1 & 1 \\
\hline PMN & -20 & 4 & 1 & 0 & 0 & 0 \\
\hline disc+ball & -10 & 5 & 2 & 2 & 1 & 0 \\
\hline
\end{tabular}


Table 5: Detection results of the four metal detectors for the lane with magnetite.

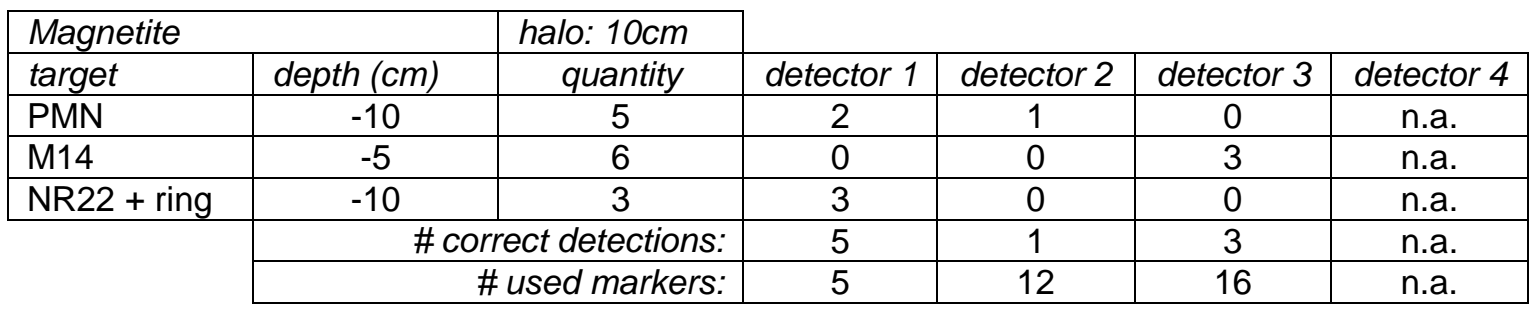

\section{CONCLUSIONS}

The set-up and execution of detection performance tests of the five commercial-off-the-shelf detectors in the framework of the procurement process has led to the following conclusions.

- In the short time frame available for the tests, detection performance tests were set up and executed that yielded usable information for the selection in the procurement process of metal detectors for countermine operations. Existing test lanes at TNO, The Hague, were used, which were only slightly modified for these tests.

- Although the magnetite may be unrealistically severe for metal detectors, one detector was able to detect some of the targets with a medium metal content without any false detections.

- The results of the test show clear differences between the detection performances of the four metal detectors.

- Although not discussed in this paper for reasons of confidentiality, a plus value of detectors that combine metal detection and ground penetration radar can be shown with the test procedure used.

\section{Acknowledgements}

AJS wishes to thank Peter Fritz and Yolanda Barrell for their support in the set-up and execution of the tests and the MoD for financial support. AJS and JHJR thank the operators of the tested detectors for their efforts in order to obtain the best results.

\section{REFERENCES}

1. Deelstudie Mijnbestrijding (Study on countermine; in Dutch), October 9, 2002, RNLA, Army Staff.

2. General Purpose Hand-Held (Mine) Detector (GPHHMD), Program of Requirements, POR number 014400, RNLA, 20-04-2004.

3. Special Purpose Hand-Held (Mine) Detector (SPHHMD), Program of Requirements, POR number 014401, RNLA, 20-04-2004.

4. $\quad$ Sophisticated test facility to detect land mines, Wim de Jong, Henk A. Lensen, Yvonne H.L. Janssen, Proc. SPIE Vol. 3710, 1409-1418 (1999).

5. International Pilot Project for Technology Co-operation, Final Report, ed.s Y. Das et al., EUR 19719 EN, 2001.

6. In-soil tests International Pilot Project for Technology Co-operation (IPPTC) in metal (mine) detection, technical report, A.J. Schoolderman (TNO) and maj P.J.M. de Veer (RNLA), FEL-00-A246, October 2000.

7. CEN Workshop Agreement, 'Humanitarian Mine Action - Test and Evaluation - Metal Detectors', CWA 14747, June 2003.

8. Metal Detector Handbook for Humanitarian Demining, Dieter Guelle et al., European Communities EUR 20837, 2003, ISBN 92-894-6236-1. 